dimethyl derivative of hydroguinone phthalein and the methyl derivative of phenolphthalein, and although the latter only contained half the amount of methoxy group, the compounds formed were more unstable. It seemed as if the methyl ester of phenolphthalein might partially decompose without losing colour, but if it were allowed to stand with alcohol for any length of time the colour disappeared.

Mr. H. G. BENsETT sail tho subject was of considerable practical importance in leather dyeing. Ho had tried tho methyl ester as an indicator and found that although there was apparently no difference in aqueous solutions it was more sensitive in nlcoholic solutions than phenolphthalein. He suggested that some of the higher esters of the series such as tho ethyl or propyl ester might be more stable than the methyl compound, and might possibly be equally or more sensitive ns indicators.

Mr. C. P. Frss said that some years ago some French chemists were working on the nbsorption spectrn of the triphenylmethane dyestuffe, and he would like to know if reseurches in this direction had thrown any light on the probability of the truth of the guinonoid theory.

Prof. A. G. Green, in reply, said thint phenolphthalein was of course no exception to the law of jonisation, but colour was not produced by ionisntion. Reasoning a priori, why should a colourless salt on dissocintion give a coloured ion ? Colourless salts of phenolphthalein could be obtained, which might be dissocinted in solution but would only gire a colourless ion. The physical chenist considered the colour ehange was duo to ionisation, but colour chemists thought that a change in the structure of tho benzene molecule took place. 'The stability of the plenolphthalein ether largely depended on the absence of all acid, but the presence of the merest trace would render it unstable. The colour did not change at first although Mr. King said it might lose methyl. He thought it probable that finding of dyestuffs might be due to a change from the quinonoid form to the benzenoid form. The triphenylmethane dyes were most fugitive, but fading could not take place unless at least a trace of moisture was present. Mr. Bennett had suggested that some of the higher homologues of the methyl ester of phenolphthalein might bo more stable and he thought that this would probably be the ense. Such a member as the anyl or benzyl derivative would most likely retain exactly the same properties as tho methyl ester along with superior stubility.

Meeting held at Leeds on Monday, December $0 / h, 1907$.

[ BIR, F. W. URANSON IN TIE CHAIK.

\section{AN ACCURATE FORM OF GAS ANALYSIS APPARATUS FOR COMMERCIAL AND O'THER PURPOSES.}

BY WILLIAM A. BONE, PII.D., D.SC., E.R.s. AND MOHARD V. WHEELER, A.sc.

The nuthors make this communication in response to repeated requests for a convenient and not too costly adeptation of the gas analysis apparatus used throughout their researches on combustion, which shall meet the daily requirements of a commercial research laboratory.

The authors' research apparatus, which was erceted ten years ago, (vide Bone, Proc. Chom. Soc., 1898, 154), embodied, in its essential fertures, the principles of that originally dovised by tho late Sir Edward Frankland, and subsequently modified by Professors Herbert M'Leod and H. B. Dixon. Since its erection it has been in continuous daily use in the laboratories of Owens College, Manohester (1898-1906) and the University of Loeds $(1800 / 7)$, for upwards of 3000 analyses, including explosion analyses of mixtures of axygen with such hydrocarbons as methane, ethane, ethylene, acetylene, propano, propylene, trimethylene, butane, and butylene, as well as the analysis of the products of the partial combustion of these hydrocarbons, and of different.forms of producer gas, water gas, natural gas, oil gas, coal and coke-ovon gas, septic tank gas, blast furnace gases, otc. It has proved to be so admirably adapted to all these varied require. ments, that the authors decided to introduce such modifications in details as would, without sacrifice of its essential fentures, bring it within rench of most technical laboratories, and now after more than a yenr's daily trial of tho modified apparatus, they feel that it can bo confidently commended to all who desire a thoroughly reliablo instrument.

The essentinl requirements of a "commercinl " apparntus, with any claims to precision are (I) nccuracy of measurement, including, of course, the maintenance of a constant temperature in the eudiometer, (2) sufficient capacity to allow, in an explosion annlysis, of the proper dilution of the "explosive mixture" ("Knallyas") with excess of air or oxygen, (3) absorption arrangements such as will permit of the use of small volumes of freshly propared (i.e. previously unused) reagents, (4) rapidity of action, (5) adaptability to gases of widely different compositions and richness, and (B) simplicity and general convenience of design and worling arrangements. Muny, if not most, of the forms of apparatus commonly in use are vory deficient in regard to the second, third, and fifth of these requirements, however sutisfactory they may be in other respects. whilst some of them involve the use of absorption vessels which are either needlessly elaborate or linble to frueture. 'The authors bave duly considered all these points, their aim being to

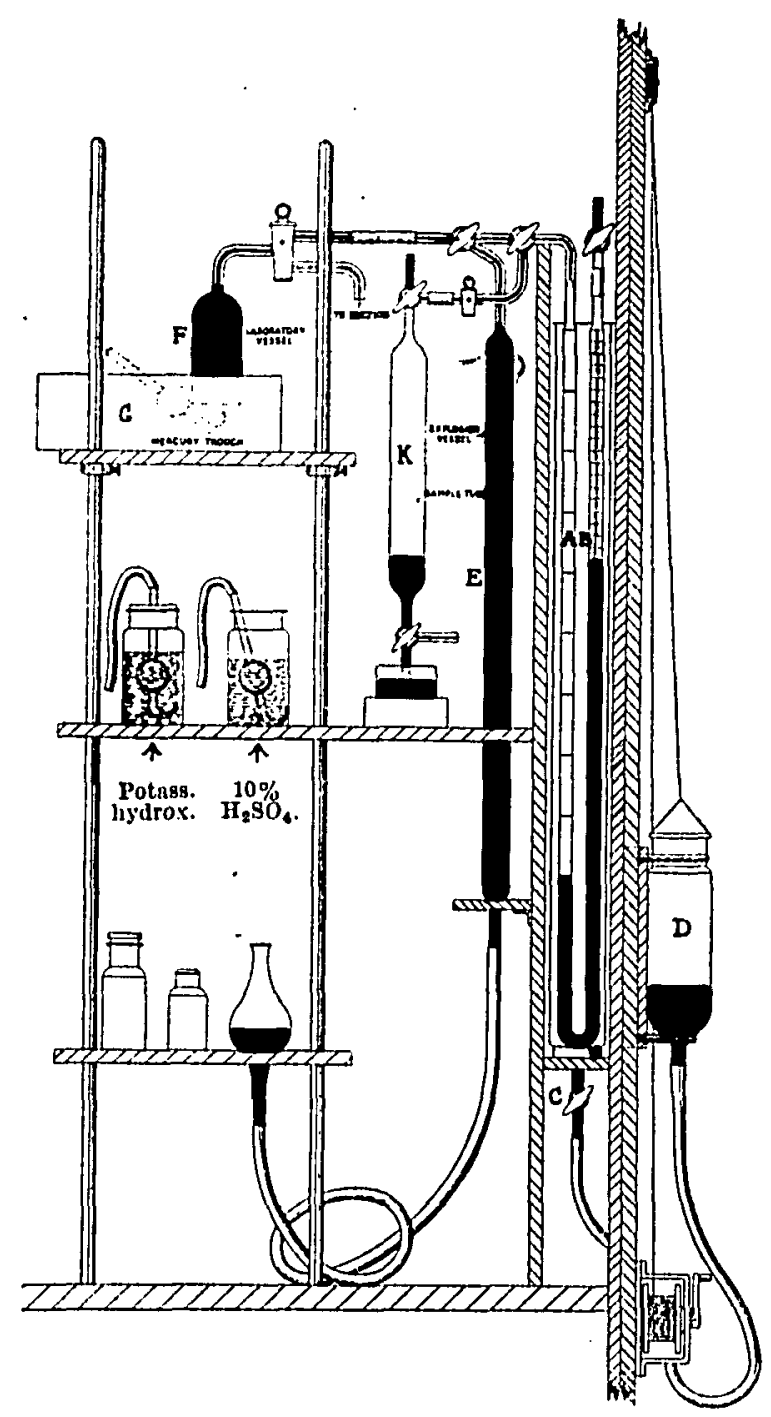


reduce everything to its simplest terms consistent with convenience and accuracy of working.

The general character and arrangement of the various parts of the apparatus will be rendily understood, with the nid of the accompanying diagram, by all who are familiar with the methods of gas-analysis. It comprises, essentially, three parts, viz. (1) a water-jacketed combination of measuring and pressure tubes, $A$ and $B$, communicating, through the glass tap, $\mathrm{C}$, with the mercury reservoir, $D,(2)$ an absorption vessel, $F$, standing over mercury in a mahogany trough, G, (3) an explosion tube, $\mathrm{E}$, fitted with firing wires, and connected with a separate mercury reservoir, $H$. All the connections between $A, E$, and $F$ are of capillary bore throughout, with suitable glass taps wherever necessary. The dingram also shows how conncetion is made between the measuring tube, $A$, and the special "sampling tube," $K$, whencver the latter is employed for the introduction of the sample under examination. The sample may also be introduced into the apparatus, from an ordinary test-tube, under the wide open end of the absorption vessel, $F$, which has been previously filled with mercury. Before commencing an analysis, the whole of the apparatus, including all the connections between $A$. $\mathrm{B}$, and $\mathrm{F}$, is completely filled with mercury, and, needless to say, the whole of the subsequent operations are conducted over mereury.

The various parts of the apparatus are suitably mounted on a strong wooden stand (maliogany, onk, or teak), with four vertical steel rods supporting the shelf upon which the mercury trough, $G$, rests, the same rods also carrying another shelf for rengent bottles. Proper provision is made for the raising or lowering (to the ground level, if required) of the mercury reservoir, $D$, by means of a wooden carrier with suitable pulley and ratchet whecl. The whole apparatus stands in a wooden tray $2 \mathrm{ft} .4 \mathrm{in.}$ by $1 \mathrm{ft} .6 \mathrm{in}$. with 1 in. raised sides.

Tho salient features of the working of the apparatus are as follows : - .

(1) 'The principle of metsurement emplored is that first introduced into gas unnlysis by legnailt, and sub. sequently adopted by Sir Jidward Franiliand, niz., the mensurement of the pressure of the gas (in m.m. of mercury) at constant volume. For this purpose the gas is brought to a certain "constant volume" mark in the uncesuring tube, A (by suitable manipulation of the mercury reservoir $D$ and the taj, C) and its pressiure read oft on the pressure tube, 13. There are a series of such " constant rolume" marks on $A$, each coinciding with a $100 \mathrm{~mm}$. mark on the pressure tube, 13 (i.c., with $0,100,200$, dec., min.), so that the actual pressure of the gas is given by subtructing from the "pressure rending "the numbers 0,100 , or 200 , etc.. according to the particular constunt volume mark selected for the analysis. The tubes $A$ and $\mathrm{l}$ are made in one piece, which is surrounded by a witer jnekot, and their inner surfaces are kept moist. with very dilute sulphuric acid (1 in $\mathbf{0} 0)$ as a precention against the accidental fouling of the measuring tube, with all:alis, and it is obvious that the wetting of $A$ and is with the same liguid climinates the infuence of water vapour upon the gas mensurements, the various pressures representing those of the dry gas under examination. 'J'he tap closing the upper end of the pressure tulve is connected with it by means of stont rubber pressure tubing, a dovice which gives a perfently tight joint with suflieient elusticity to prevent fracture in case the mercury in $B$ is inadvertently allowed to run up the tulse with cinusual velocity. The tup in question tho allows of tho vacuum being easily made in $B$ whenever necessary. The ndvantages of this mode of neasurement over the more usual method of dotermining the volumo under atmospherio pressure aro twofold, viz. (1) it allows of the ne of smaller volumes of gas for an analysis--thus from 5 to 10 c.c, of gas can bo mado to have a pressure of $100 \mathrm{~m} . \mathrm{m}$., according to the particular volume mark selected, and this pressure can easily be rend off to within $0.2 \mathrm{~mm}$. without employing a telescope, and (2) tho measurements are, of course, indepondent of the baromets ic pressure and at the same time are unuffected by tension of aqueous vapour.

(2) 'I'he length of the pressure tube, $\mathrm{li}$, (about $700 \mathrm{~mm}$ ) amply provides for the proper dilution of the "explosive mixture" in an explosion analysis.* Thus in the annlysis of a coal yas containing (say) carbon dioxide, 0.5 , unsaturated hydrocarbons, $5 \cdot 5$, carbonic oxide, $6 \cdot n$, hydrogen, $55 \cdot 0$, and methane, $33 \cdot 0$ per cent. respectively, if an amount of gas were originally taken corresponding with a pressure of $120 \mathrm{~mm}$. at the constant volume mark, $O$, then after removal of carbon dioxide and monoxide, and unsaturated hydrocarbons with suit able absorbents, the residual $105 \cdot 6 \mathrm{~mm}$. of mothano nnd hydrogen would give $217 \cdot 9 \mathrm{~mm}$. of "Knnllgas," which could be diluted with the $350 \mathrm{~mm}$. of excess oxygen necessary to ensure accuracy in the subsecpuent explosion. The importance of capacity is, of course, even greater in the caso of a rich oil gas, or in the annlysis of acetylene, where very large dilutions are necessury:

(3) The arrangements for the various " absorptions" are of the simplest. Instend of using a number of large absorption vessels cuch containing a partinular reagent which is used unchnnged many times over in suecessive annlyses, all the absorptions are carried out over mercury in tho one ahsorption veses, $F$, in each enge with a com. paratively small rolume of the particular 1eagent which is always used fresh and is at onee diseurded after use.

I's facilitate the introduction of the varinus reagents, and the rinsing out of the absorption vessel with water or dilute sulphuric unit in silu between each successive rengent, the wide $(o p e n)$ end of the vessel is immorsed inder the mereury in the trough, $G$, whilst the top terminates in a capillary three-way tap, $k$. One of parallel branches of this tap communicates, through $a$ stout rubler joint, with the measuring vessel, $A$, und the other with a water pump, a large bottle being inserted between the pump and the absorption vessel to serve as a trap for either the mereury or the reagent which is being discarded after use. The insertion of a top between the pump and the bottle obviates the necessity of tho continuous exhaustion of the latter, a single exhaustion at the outset of an malysis being ull that is required.

lirom 2 to $\pi$ c.c. of the particular reagent to bo used is introduced into the absorption vessel (previously filled with mercury), by menns of a stitable pipette, from below the surface of the mercury in the trough. Any minute bubble of nir acciclentally introduced with the rengent can be got rid of by cautiously opening the uranch of the tap, $k$, lending to the above nentioned evhausted hottle; the same device allows of the complete withdrawal of the reagent after use, without taking down tho absorption vessel, and also of the rinsing out of the latter in silu with water, or dilute sulphurie acid, before the next rongent is used.

In this way, using small yuantities of each successivo rengent always in a fresh condition, and washing the vessel out in situ between each reagent, a series of absorp. tions can bo quickly carried out without disturbing a single connection in the apparatus. It inny also be added that long experience has proved that the use of such rearents as a solution of bromine (in potassium bromide) for the alsorption of unsaturnted hydrocnrbons, is unattended with diffieulty.

(4) In point of rapidity of action, combined with nceuracy, the apparatus will compore favourably with any other type. An analysis of producer gas can bo ensily carried out in 45 minutes, and one of conl gas in about an hour.

(5) There are no compliented parts about the apparatus to oceasion trouble, and tho several parts can be readily detuclied for eleaniug purposes.

(0) The apparatus is well adnpted for the analysis of almost every kind of combustible gaseous mixture, ordinnrily met with in technical practice.

Discussios.

Mr. J. W. Cons said that no branoh of technical analysis had doveloped more in the past few years than the anulysis of gases, on account of the growing convistion that

- If tho apparatus is required for the analysis of such diluted gases as producer gas or blast-furnace gas onjy. the length of the pressure tube need not exced $400 \mathrm{~mm}$., in which case the lengths of the measuring tube, $A$, and the explosion tube, $\mathrm{F}_{2}$ could be correspondingly: diminished, with consequent reduthon of the total height of the npparatus above the working bonch. But. such a reduced npy
rioher gnses. 
weientifie control was cssential for the economical use of fuel. Tho development wns howerer, mainly in quantity and not in quality. The Hempel apparatus was a good form for control work on ordinary combustion jorocesses, and was ensy to manipulate, but others must have felt the need that he himself had experienced, for some mose delicate apparatus, what he might call a reference apparatus, for use in determining with certainty the effect of comparatively slight alterations in the conditions of some process. He nssumed that this apparatus wos intended for reference rather than for control purposes. In comparing the results olstained by the anthors in the analysis of produccr gases with those generally obtained from the Hempel apparatus, the inethane seemed to come out always higher, usually about 1 per cent. Why was this? Could eomparison be made between the heating power us calculated from unalysis, and the same as deiermined by gas calorimeter; he had always found the results from gas calorimeters, although comparable with one another, to be low compared with those from nnalysis, and more so than could be explained by the radiation losses of the enlorimeters. Finally he should like to compliment the authors on some of the novel detals of the apparatis, and to welcome the paper as the first contribution from the new Fucl and Metallurgical Department of the leeds University, to the Socirty of Chemical Industry.

Mr. II. Farneer pointed out that the apparntus was by no means a portable one. It was suitable for an expert chemist to use. The wasling out of the vessels by ueans of the vacmum bottle was an ndvantage, ald the use of mercury made possible greater accuracy. Water was very convenient when the apparatus had to be carried about, and for certain work the results were near enough.

Mr. F. W. Pichardsox welcomed the apparntus since he lad to suffer a good deal from the shortcomings of other forms of upparatus for gas analysis. He noticed the large number of trus but was pleased to hear these were not likely to get out of order. Ho asked what lubricant Prof. Bone used, and if the npparatus was suitable for extracting dissolved gases from liquids. Hnd Prof. Bone found trouble by the nction of bromine on the mercury used : Mercury whs clean and gnve aceurato results, and he was surprised to see how often water or brine was recommended in its place.

Mr. W. Iowsos inquired what amount of concordance could be obtuined between the results ohtained by" exploding the unabsorbed residue of a coal gas in three or foilr fractions.

Mr. C. J. Fiss asked what time was necesnary for the gus to remuin in contact with the absorbent and if shrking was required. He had always found two treatments with separate lots of ammoniacal cuprous chloride in separate Hempel pijettes necessury to remove carbon monoxide completely.

Prof. lí. A. Bowe, un reply, said that all the points ruised during the discussion had been carefully considerce in designing the apparatus. and many years' experience with he own reseurch appuratus, of which the present form was an udnptation, had convinced him of its relinbility.
It was not perhaps an apparatus to put into the hands of a works foreman, or possibly even into the hands of $n$ novice in the lnboratory, but anyone with ordinury manipulative skill and practice conld be entrusted with it. It hind been in daily use as a control apparatus in. connection with a large producer plant under Mr. Wheeler's eupervision for more than a yenr, and had given the grentest satisfaction. The Hempel apparatus was. in his opinion, quite unreliable and uscless, except for very rough work, and he was not surpirised to hear about the low methane results for producer gas obtained with it. He should never think of placing any reliance on results obtaincd with either the Hempel or the Orsat apparatus. where the estimation of small quantities of any given constituent was concerned, or where small differenecs in composition had to be detected. He had suecessfully applied the most rigid tests to his reseurch appuratus with hydrogen contrining known small percentages of methane. Aloreover, whenever ho had had occasion to supplement gas analyses by calorimetric tests during producer trials, he had found close agreement between the two sets of results. Comparative unalysez of the snme samplo of gas with the research apparatus and with the present apparatus sliewed gourl agreement, amb aithough the latter was not quite capable of the same degrec of refinement as the resenrch apparutis, which, indeed, was much more costly, it was nevertheless, so far ns his experience went, a thoroushly reliable instrument. With regard to the absorption of carbon monoxide by means of an ammoniacal solution of cuprous chloride, evervthing deponded upon the cars taken in preparing the solution. He always used a freshly prepared (i.e., unued) solution, containing ammonium chloride, of such activity that it absorbed carbon monoxide ulmost as rapidly as caustic potash absorbs carbon dioxide. Careful experiments had shown, morrover, that after two suecessive treatments of a gascous mixture contnining large quantities of carbon monoxide with such an active solution, the amount remaining unabsorbed was negligibly small. He often used $a$ solution of bromine in potassium bromide for the absorption of unsaturated hydrocarbons, but found no dilliculty at all with it. With regard to taps, if thees were carefully selceted by $n$ competent judge, and kept lubricated with a solution of india-rubber in vaseline, and especiully if the whole apparatus was regularly wushed out with diluto acid after cach analysis-an operation which could be performed in less than two minutes-no trouble would arise. People who experienced trouble with stop. cocks sticking had largely their own carelessness to blnme. There could bo no doubt but that gases must be analysed over mereury if aceuracy was desired, and he personally never used any other liquid in a gas analysis apparatus : the best substitute for mercury would porhaps be a mixture of equal volumes of glycerin and water. He could not agree that water by itsclf was "good enough" for evon rough work. In these days when gaseous fucls played so impurtant a part in indistrinl operntions the need of exact methods of gas analysis could not be too much insisted on, and tho present nppuratus was designed to mect thint need.

\section{Journal and Patent Literature.}

Patent Sproifioations may bo obtained by post by remitting as follows :-

English $-8 d$. each, to the Comptroller of the Patent Omee, C. N. Dalton, Esq., Southampton Buildings, Chancery Lane, London, W.C. Dnited Stales. - 1s. each, to the Secretary of the Society.

French.-1 Ir. 25 o. each, to Belin et Cie, 50, Rue des Francs-Bourgeols, Paris (3e.).

\section{I.-PLANT, APPARATUS, AND MACHINERY.}

\section{PateNis.}

Drying and grinding matorinls. O. Imruy, Jondon. From Soe. of Cluen. Industry, Basle, Switzorlnnd. Eng. Pat. 9741, April 20, 1907.

A romizontsu oylinder witl open ends olosed by perforntod plates is surrounded ly $n$ henting jncket und is mounted so that it can be rotuted within an aiv-tight casing in which a vacuwm is maintained. Within tho cyliniter aro a number of balls, or "grinding bodies" of steel, or othor suitable material, which crush the material as tho oylinder is rotnted. The material to be trented, which may contain any quantity of moisture, is fod by suitable means, continuously and without breaking the rucuum, into one end of the cylinder. It is ground and dried and continuously discharged from the other ond of tho cylinder into the first of two valved chambers, which form an nir. lock, so that the drind material can be continmously oxtracted withont breaking tho vaumum. Tho vapolir given oft is discharged from that end of the casing at which the moist mnterial enters and it travols in thos 